Example:

Height of eye $50 \mathrm{ft}$. , dip 6.9 (1) Measured angle $15^{\prime}$
(2) , $120^{\prime}$

$$
\begin{aligned}
& \frac{50 \times 0.565}{21.9}=1.3 \text { miles } \\
& \frac{50 \times 0.565}{126.9}=2.23 \text { cables }
\end{aligned}
$$

This can be used for checking radar ranges on low scales or for station keeping, \&c.

\title{
The Improvement of Navigation Lights and Signals
}

\author{
Bernard Hayman (Editor, Yachting World)
}

Douglas Lindsay's article in the Journal $(20,249)$ raises numerous interesting points and I agree with much of what he says, but he has orientated himself so strongly towards the problem of the big ship that he has recommended a change that would bring complete confusion at the smaller end of the scale.

The most useful points $\mathrm{Mr}$. Lindsay raises are the need for increased ranges for ships' navigation lights, coupled with the dangers of extraneous lights. Both these points apply in their own way to small vessels. However, I disagree with $\mathrm{Mr}$. Lindsay's article where he refers to the meaning of a single white light. He starts his argument by saying:

'There can be few things which the officer of the watch at sea more dreads meeting than the amorphous blob of white light all on its own. It can be anything from the stern of the Queen Mary (disappearing rapidly) to a small boat hurling itself to instant oblivion beneath one's bows. It has many other meanings between these extremes, and owing to its totally negative form does not tell the navigator straight away anything whatsoever about how he should interpret it.'

But this is not so because, under the present rules, a single white light always means that the vessel seeing it must take avoiding action.

Mr. Lindsay then goes on to recommend that the single white light should be reserved solely for small craft, such as are defined in Rule 7.

In the first place, I can hardly believe that $\mathrm{Mr}$. Lindsay really wants to give 'all power driven vessels of less than $65 \mathrm{ft}$. and all vessels under oars or sails of less than $40 \mathrm{ft}$.' automatic right of way over all other shipping, which is what his proposal means. But, even worse, what about the men on watch in the small vessels themselves? The essence of the present Rule of the Road is that a ship's 
lights tell us (a) how a vessel is heading and (b) what type of vessel she is. A single white light would tell us neither of these two things. How is a boat in a fleet of small boats expected to manœuvre in relation to the others without any indication of whether any of the single white lights seen ahead is coming or going ?

Following Mr. Lindsay's proposals, it might be a relief for a yacht to be given right of way over all larger ships, but the resulting chaos from one's own kind would be an uncomfortable alternative.

\title{
Signals for Vessels in Sight of One Another
}

\author{
D. A. Rodger \\ (Second Officer, P. \& O.)
}

I HAve been following the articles on this subject in the Journal 1 with some interest and hope that the personal views of one comparatively junior officer may be of some interest.

It is implicit in all these articles that, except in the close-quarter situation which the Rules are surely designed to prevent, the sound signals are unsatisfactory. What is not stated in so many words is that, international conferences notwithstanding, Rule 28 (a) is more observed in the breach than otherwise. I cannot of course be sure, but I suspect that this has been so since electric navigation lights superseded oil in general use, thus increasing the recognition range and allowing avoiding action to be taken at greater distances. There is also the natural human, if not legally commendable, desire to let sleeping captains lie.

I am sure that, of the suggested signals, the simple flashing light of the appropriate colour is by far the best. The directional arrow concept seems an oversubtle solution to the problem. As an officer on watch, what I want is a flashing light which I switch on to indicate that I am starting a turn, and which I switch off, or preferably which switches itself off, when the turn is complete. The other ship would see by the flashing that I was turning, or just about to turn, and when the flashing stopped he could tell by my aspect how I was heading. If thought desirable, white flashes could be used to indicate 'my engines are going full speed astern'. I should want these signals to be visible clearly by day, yet not to be too bright by night, so some form of dimming arrangement would have to be incorporated.

The variations of short and long flashes put forward by Lindsay would seem to be an unnecessary elaboration, and the warning lag of two minutes suggested by Commander Parmiter is vulnerable when speeds in excess of 20 knots give an advance of more than $\frac{3}{4}$ mile in that time. Technically it should not be difficult 